\title{
OBSTRUCTION OF THE ESOPHAGUS IN CHILDHOOD
}

\author{
BY \\ WILFRID SHELDON, M.D., M.R.C.P., \\ and
}

A. G. OGILVIE, M.B., M.R.C.P.

(From the Hospital for Sick Children, Great Ormond Street, London.)

The condition broadly defined by the title of this paper was brought to our notice by the clinical observation of six children at the Hospital for Sick Children, Great Ormond Street, all of whom presented the symptoms of wasting, constipation, and regurgitation of undigested food from the cesophagus. Although the term ' cardiospasm ' was applied to these children for the purposes of the hospital records, the underlying morbid condition which existed at the lower end of the cesophagus remained in most cases obscure. In the hope of reaching a clearer undorstanding of the pathological basis of these cases, the hospital records were searched, and six additional cases of similar nature were found. Of the total of twelve children with osophageal obstruction, five have died. With one exception these have come to post-mortem examination, and the pathologist's reports have been available. In addition, radiological evidence has been forthcoming in all but two cases.

To be complete, this article should include that form of obstruction met during the first two weeks of life due to complete atresia of the oesophagus. Instances of this condition have been frequently recorded, and in $1917 \mathrm{Cautley}^{1}$ published a full review of the subject. The symptoms are well defined, and the condition is incompatible with life, so that further allusion to this group will not be made. Acquired stenosis such as follows upon the ingestion of caustics is also excluded from consideration.

The study of the cases at our disposal was simplified by grouping them according to the level in the osophagus at which the obstruction occurred, and we shall consider them in this manner. The first and largest group consists of 10 children who had obstruction at the level of the seventh thoracic vertebra, halfway between the level of the bifurcation of the trachea and the diaphragm. It is to these cases that we wish to draw particular attention, because they form a clearly defined clinical entity, which is, however, apt to be confused with the condition called 'cardiospasm' or 'achalasia of the cardia.' The result is that they are often submitted to treatment which, although successful in cardiospasm, is injurious to them.

In the two remaining cases, the obstruction was at the level of the diaphragm. 
Group I. (Cases 1-10). Obstruction at level of 7'Th dorsal vertebra.

Case 1. Previously recorded by Dr. Hutchison." C. F., a male child, was admitted to hospital at the age of 3 years with a history of vomiting since six weeks old. For a week in each month the vomiting was particularly severe, occurring after each meal. Constipation was a constant symptom, varying with the vomiting.

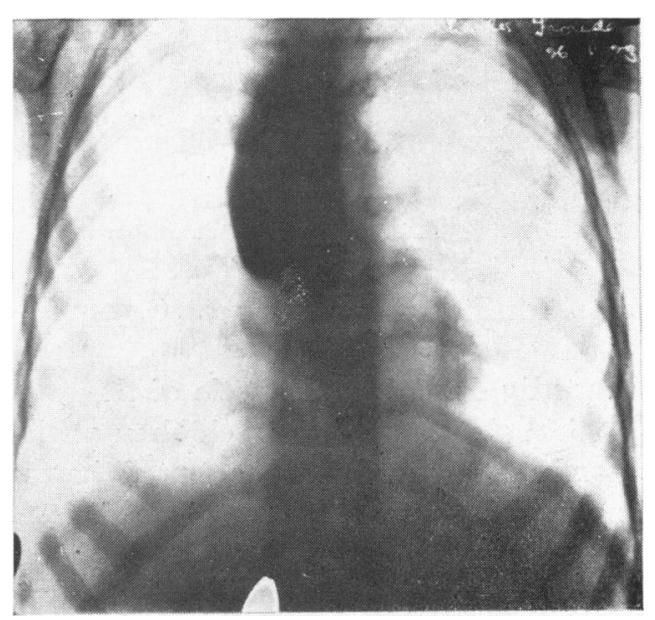

Firi, 1.

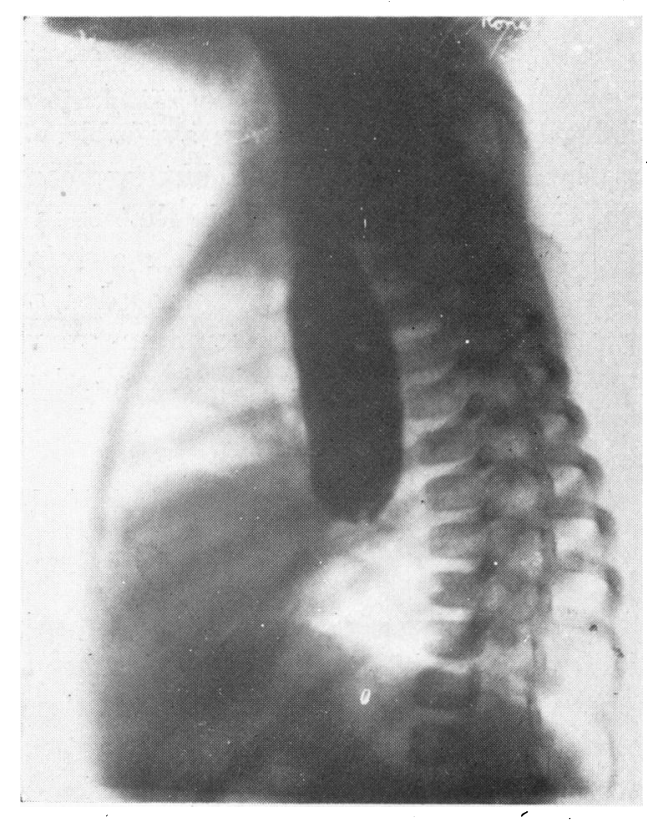

FIr. 2.

On examination the child was very undersized (weight $15 \mathrm{lb}$.). X-ray examination (Fig. 1 ) showed a bismuth meal retained in the asophagus at the level of the 7 th thoracic vertebra, well above the dome of the diaphragm. The child was given a fluid diet, but continued to vomit every day, and a month later developed a fatal broncho-pneumonia. Bougies were not passed in this case. 
At the post-mortem examination, a hard fibrous constriction of the cesophagus was found at a level of $1 \frac{1}{2}$ inches below the bifurcation of the trachea, the portion of the osophagus above the constriction being dilated. Microscopical section through the constriction was not made. The case was regarded at the time as an example of congenital stricture of the osophagus.

Case 2. R. B., male, was admitted to hospital for the first time at the age of 19 months. Vomiting, which dated from birth, had been worse since weaning on to solid food at 12 months of age. Constipation had accompanied the vomiting.

On examination the child was thin, and weighed $15 \mathrm{lb}$. There were no abnormal physical signs. Examination by X-ray (Fig. 2) showed a bismuth meal held up in the resophagus at

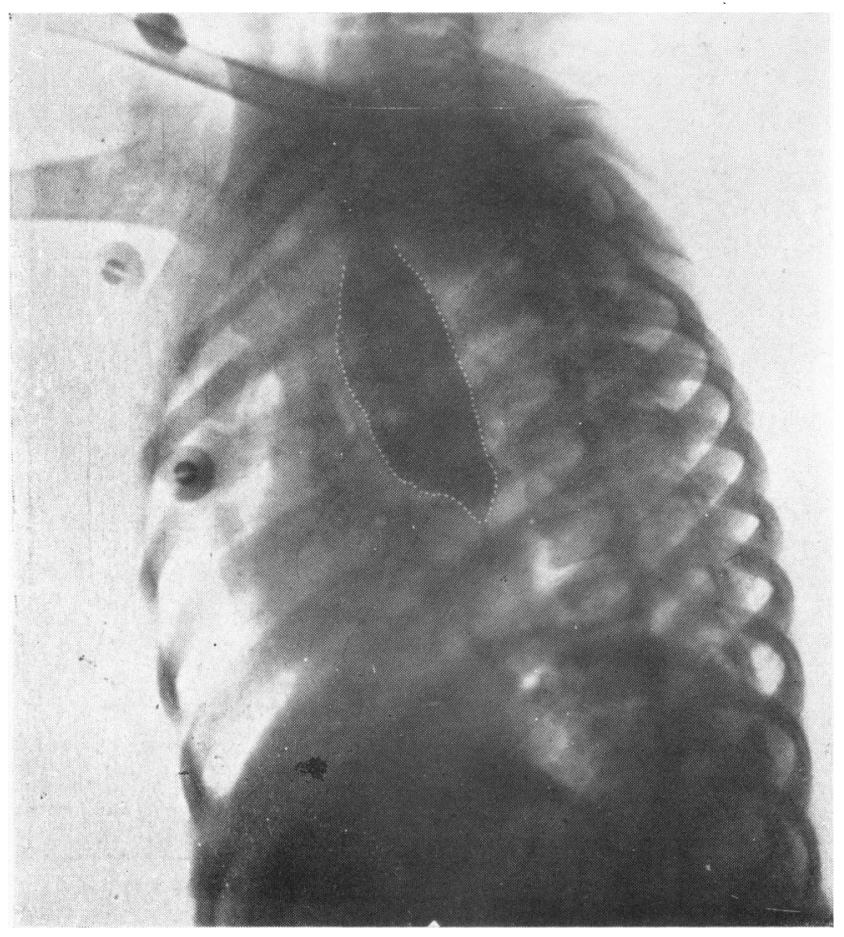

Fil:. 3.

the level of the 7 th thoracic vertebra, a full inch above the diaphragm. A strictly fluid diet was ordered, and the vomiting was gradually overcome. During the next 5 months the weight increased to $20 \mathrm{lb}$.

A year later the boy was ro-admitted because of a return of persistent vomiting during the previous 3 weeks. An X-ray photograph demonstrated that although the oesophagus was less dilated, the level of obstruction had not. altered. A fluid diet was again established, whereupon the patient improved.

The boy was seen again at 6 years of age, when it was learned that attacks of vomiting had recurred at gradually lengthening intervals. There had been no vomiting for the last 10 months. The boy looked well, his weight was $40 \mathrm{lb}$., and an X-ray screening showed no delay in the passage of an opaque meal into the stomach.

It would appear that in this child the cesophageal obstruction underwent a slow cure. The passage of bougies was never attempted, the only line of treatment being prolonged persistence with a fluid diet. 
Case 3. K. A., male, aged 3 years, was admitted to hospital with a history of vomiting immediately after meals since he was 10 days old. Vomiting had become worse after weaning at 3 months of age. Growth had been accompanied by great weakness, so that he was unable to sit up until 12 months, and did not walk until 3 years of age. Constipation had been a constant feature.

On admission he weighed $17 \mathrm{lb}$. The muscular weakness was so pronounced that the diagnosis of amyotonia congenita was suggested, and the cesophageal condition was at first overlooked. The muscles were very small, especially the buttocks, which resembled the condition described by Miller ${ }^{3}$ as occurring in cœliac disease. For several weeks the child vomited all solid food. An X-ray photograph (Fig. 3) taken during this period showed the bismuth meal held up in the osophagus at the level of the 7 th thoracic vertebra, at least an inch above the diaphragm. A fluid diet was established, and after 3 weeks the vomiting gradually ceased. Seen 8 months later, the child had become quite active and was improving steadiy. Vomiting occurred occasionally. X-ray screening showed no delay in the passage of food through the œsophagus.

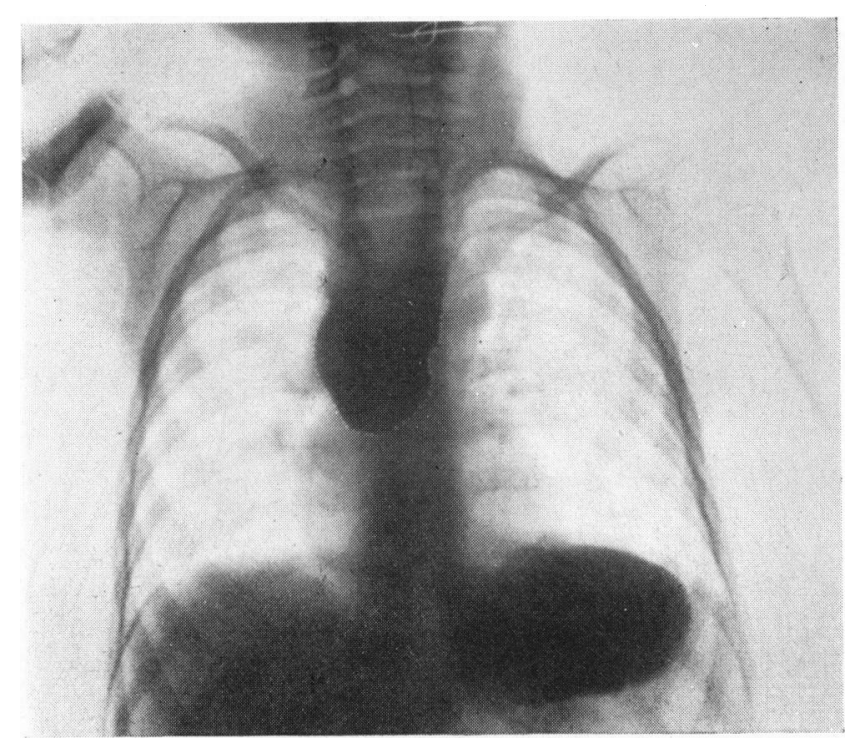

FIG. 4.

This case resembles the prezeding one in that bougies were not passed down the oesophagus. A steady improvement was brought about by insistence on a fluid diet.

Case 4. A. H., male, aged 2 years, was admitted to hospital on account of persistent vomiting since birth. Vomiting occurred immediately after meals, but there were occasional periods of freedom from vomiting, on one occasion for as long as 3 weeks. The child had lived on fluids, being unable to keep down solid food. Constipation had been a symptom since birth.

On admission the child was wasted, weighing only $14 \mathrm{lb}$. X-ray examination (Fig. 4) showed a bismuth meal obstructed in the osophagus at the level of the 7 th dorsal vertebra. A strictly fluid diet was instituted, and at first the child lost weight, and became gravely ill. Eventually the vomiting ceased, and the patient left hospital after 12 months observation, by which time the weight had increased by $2 \mathrm{lb}$. On discharge instructions were given for the fluid diet to be continued. Unfortunately it has not been possible to trace the further history of this child. Bougies were never passed on this case.

Case 5. V. D., female, was first admitted to hospital when 8 years old. Since the age of 11 months the child had never been able to take solid food, as the attempt to do so always resulted in vomiting. 
On admission the girl weighed $44 \mathrm{lb}$. The only abnormal physical signs consisted of systolic and diastolic murmurs at the apex, denoting an old rheumatic lesion of the heart. X-ray examination (Fig. 5) showed an obstruction in the œsophagus at the level of the 8th thoracic vertebra, well above the diaphragm. (Esophageal bougies were passed without difficulty into the stomach, and this line of treatment, combined with a thickened fluid diet, produced considerable improvement. After 6 weeks the child was able to keep down solid food, and had gained $3 \mathrm{lb}$. in weight.

Seen again at 11 years of age, the girl weighed $55 \mathrm{lb}$. After her previous discharge from hospital, the original symptoms had quickly returned, and she had had to-subsist on thick fluids such as custard and cornflour. A second X-ray examination showed that the condition of the osophagus had not improved during the 3 years since the first examination. Treatment by the daily passage of mercury-filled bougies was carried out, and improvement was soon manifest. After 8 weeks the weight had risen by $4 \mathrm{lb}$., and the girl could swallow and retain solid food.

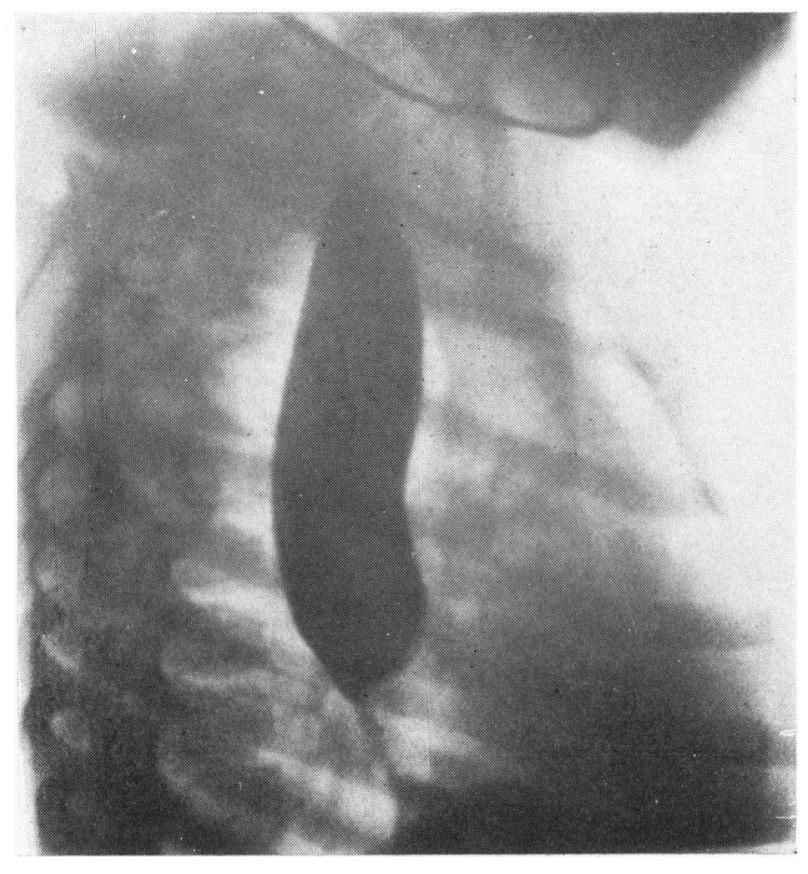

Fig. 5.

It is interesting to note the improvement that followed upon the use of bougies. Relapse soon followed the cessation of the first course of such treatment. It is as yet too soon to say whether the second course will be followed by more lasting improvement.

Case 6. B. B., male, was admitted to hospital when 5 years old, on account of vomiting after meals since birth. On three occasions he had undergone treatment in a local hospital, and on each occasion had improved on a fluid diet.

On admission the boy weighed $30 \mathrm{lb}$. There were no abnormal physical signs, and the Wassermann reaction was negative. X-ray examination (Fig. 6) showed a bismuth meal held up in the osophagus opposite the level of the 7 th thoracic vertebra. For 2 months the boy was given a fluid diet, and slowly improved. He then developed measles, and rapidly lost weight. Treatment by the passage daily of a heavy mercury-filled bougie was then instituted. At first a resistance to the passage of the tube was encountered about 9 in. from the teeth, but after a 
short delay the tube passed on into the stomach. After 14 days of this regime, the boy was able to pass the tube himself, and he was discharged home with instructions to continue the treat. ment. He succeeded in doing this for two months, and then abandoned the method.

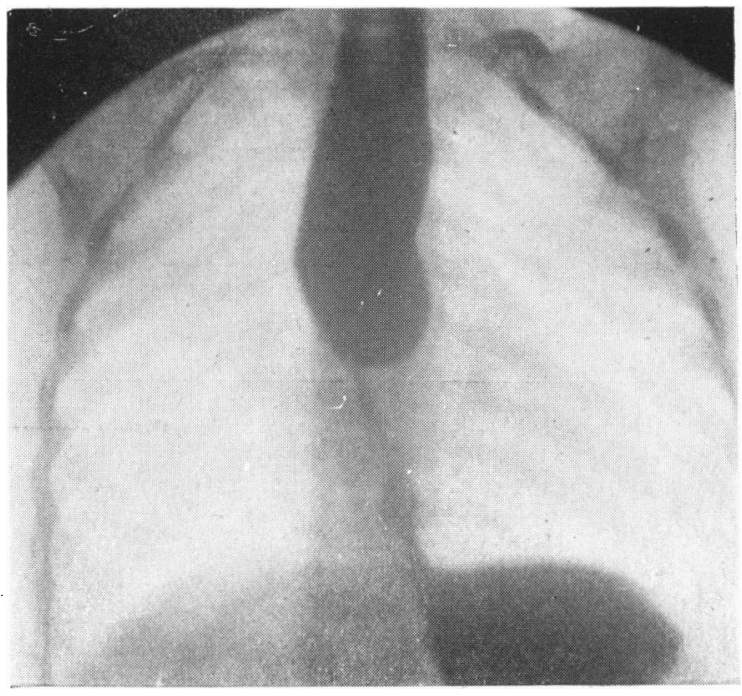

Fic. 6.

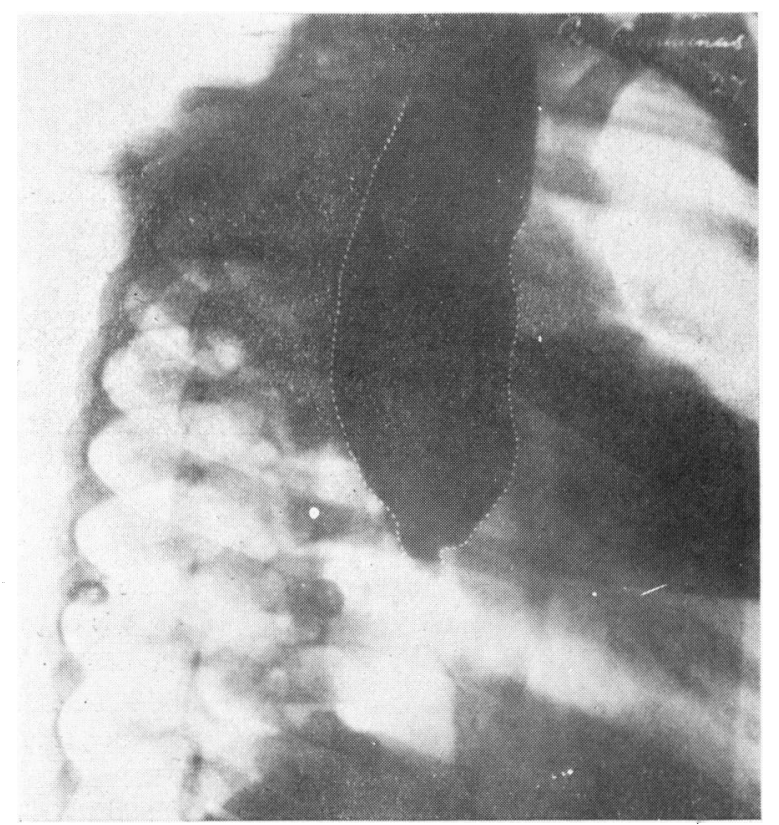

Fi:?. 7 .

A month later intractable vomiting returned, and he was readmitted to hospital. Recourse was had to feeding with thickened fluids, and slight improvement was made, although vomiting continued every day. During this time the boy survived an attack of paratyphoid fever, and it is noteworthy that from the first rise of temperature until its fall 3 weeks later he was entirely 
free from vomiting. With the subsidence of the fever, vomiting recurred daily. It was now found impossible to pass an ordinary bougie, but under anæsthesia a very fine bougie was passed beyond the stricture. The bougie was left in the oesophagus for 6 weeks, when it was changed for one slightly larger. Vomiting continued intermittently, and $\mathbf{2}$ months later the child developed a chronic laryngit is which necessitated removal of the tube. It was now possible to pass a heavy mercury-filled bougie (No. 24) without an anæsthetic, and this was done every day. At the time of writing the boy is 7 years old, and weighs $36 \mathrm{lb}$. The mercury bougie is passed twice a week, and the boy has been free of vomiting for two months. He is able to take practically a normal diet with the exception of meat.

It is difficult to assess the value of bougie treatment in this case. Following upon the first use of the mercury bougie, the degree of stricture became much worse, probably as a result of

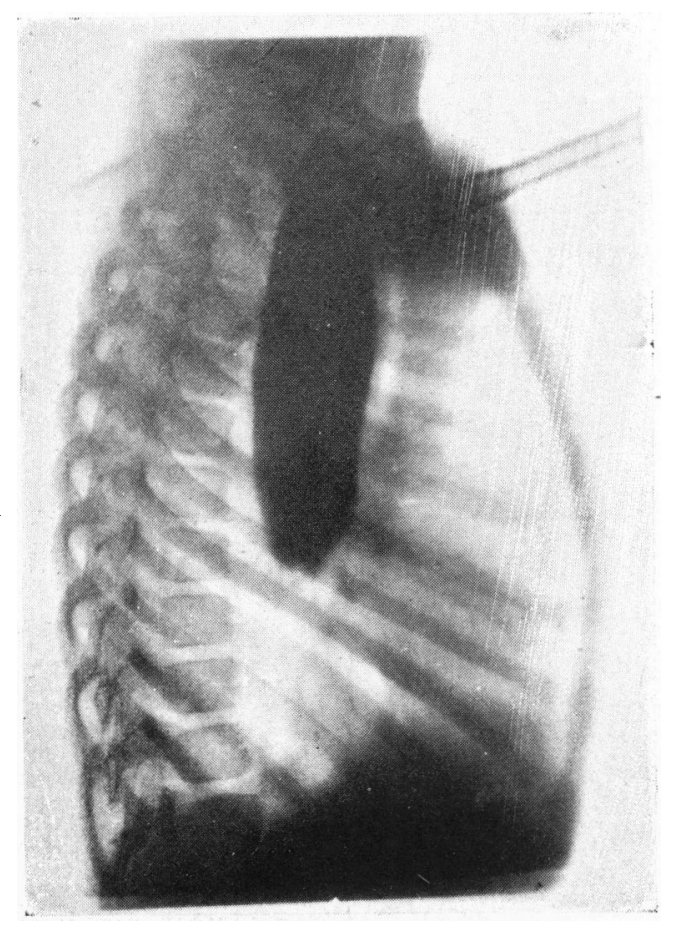

FIr: 8 .

inflammatory swelling and subsequent contraction at the original site of obstruction. By keoping an ordinary small bougie permanently in situ over several weeks, the degree of contraction had been lessened, and the improvement is being maintained by the passage of a heavy mercuryfilled bougie. Whether it will be possible eventually to discontinue using the bougie remains to be seen. The case illustrates some of the difficulties that may follow treatment by bougies in this condition.

Case 7 . G. C., male, aged $4 \frac{1}{2}$ years, was admitted to hospital with a history of bouts of vomiting which had started immediately after birth. The attacks of voniting persisted for about a week at a time, when both solids and liquids were regurgitated. The diet had consisted of fluids and semi-solids such as rice and eggs, more solid food being invariably refused.

On admission, the boy was desperately ill and extremely emaciated, weighing only $22 \mathrm{lb}$. There were no abnormal physical signs, and the Wassermann reaction was negative. X-ray examination (Fig. 7) showed an abrupt constriction in the esophagus at the level of the 7 th dorsal vertebra. 
The condition of the child rapidly deteriorated, and in spite of stimulant treatment death occurred 5 days after admission. Permission for post-mortem examination was refused.

Case 8. Previously recorded by Dr. Paterson.4. V. B., male, was admitted to hospital for the first time at the age of 5 years, with a history of effortless vomiting after meals dating from birth. Constipation had also been a feature from birth.

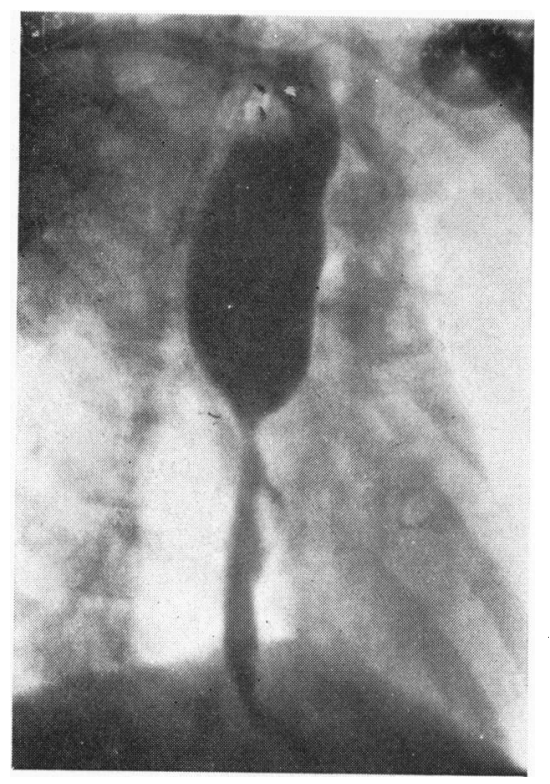

FIc. 9.

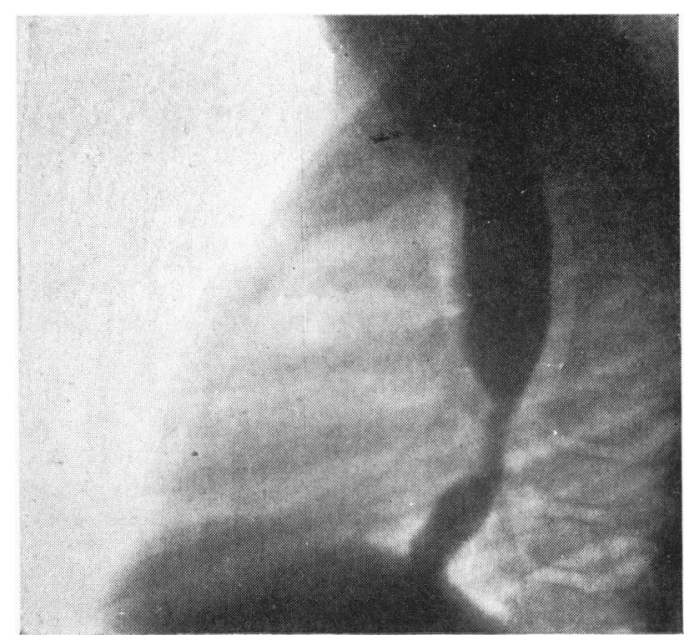

FiG. 10.

On admission the boy was very thin, weighing $21 \mathrm{lb}$. Fxamined under the X-ray screen, bougies were seen to curl up when seemingly well down the osophagus. The boy was operated upon by Mr. Tyrrell Gray, who passed a bougie down the oesophagus, opened the stomach, and grasped the lower end of the bougie with forceps. The bougie was then withdrawn a little way up into the œsophagus and the lower end of the œesophagus was dilated with the forceps. No evidence of obstruction at the cardia was found during the operation. 
Six months later the boy was re-admitted with a severe bout of vomiting. X-ray examination showed a constriction in the cesophagus $1 \frac{1}{2}$ in. above the cardia.

The child was not seen again for two years. In the meantime he had been unable to take solid food, and at times everything, including water, was returned. He was now 8 years old, and weighed $27 \mathrm{lb}$. X-ray examination (Fig. 8) again showed retention of a bismuth meal in the œsophagus well above the diaphragm at the level of the 7 th thoracic vertebra. Gum elastic bougies were now occasionally passed, but without any improvement.

The patient was not seen again until he was 13 years old. His weight was then $43 \mathrm{lb}$., equivalent to the weight of a child of 6 years, and his height was $50 \mathrm{in}$. He was still subject to attacks of vomiting, but had learnt that by eating slowly, he was able to retain more food. After this lapse of 5 years, X-ray examination (Fig. 9) showed no appreciable change in the œsophagus. He was now subjected on several occasions to the passage of a heavy mercury-filled bougie, which generally entered the stomach without difficulty, but felt as though it were gripped during withdrawal. After a few weeks, his weight rose to $47 \mathrm{lb}$,, and he was able to retain soft solids. It is as yet too soon to say whether this improvement will be maintained.

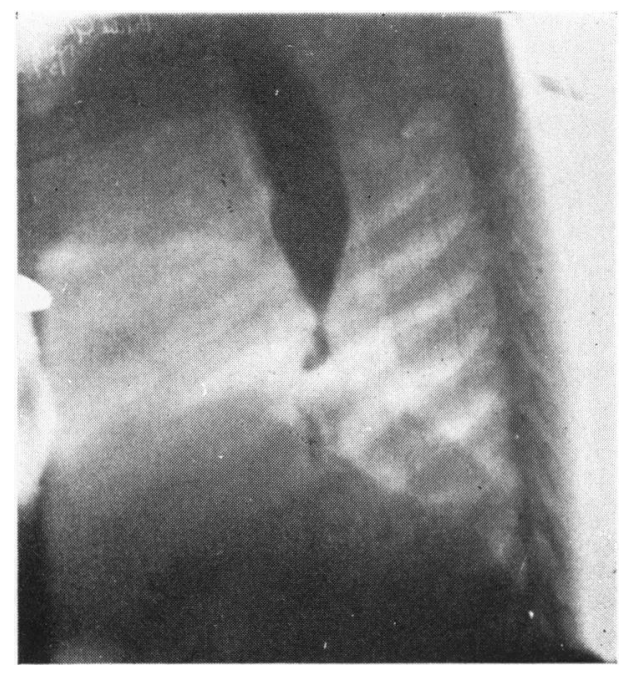

Fig. 11.

Case 9. C. B., male, was admitted to hospital at the age of 6 years, with a history of vomitin: which dated from birth. The vomiting took place generally during a meal, and was partially controlled by limiting the diet to fluids. For several months before admission, oesophageal bougies had been passed once a week, without producing much relief.

On admission the boy weighed $33 \mathrm{lb}$. There were no abnormal physical signs. X-ray examination (Fig. 10) showed the bismuth meal held up in the osophagus opposite the 7 th thoracic vertebra. During a month in hospital, ordinary cesophageal bougies were passed occasionally, and a slight improvement was recorded.

The patient was seen again 5 years later. For four years after his discharge he had continued to vomit small amounts every day, and about once a month had had a severe bout of vomiting. The attacks had gradually lessened, and for the last year he had not vomited and was able to take solid food. An X-ray screen examination showed no delay in the passage of an opaque meal through the osophagus.

The bougie treatment was in this case so irregular, and was abandoned so long before the boy eventually improved, that it can have played no part in the boy's recovery. The osophageal condition would appear rather to have undergone a spontaneous cure. 
('ase 10. H. G., female, was admitted to hospital when $2 \frac{1}{2}$ years old. She was a premature baby, and had been subject since birth to attacks of vomiting after meals. Solid food was invariably returned in an unaltered condition.

On admission, her weight was $22 \mathrm{lb}$. There were no abnormal physical signs. X-ray examination on two occasions (Fig. 11) revealed an obstruction in the ossophagus at the level of the 7 th thoracic vertebra. During 2 months in hospital she was given a fluid diet, on which the vomiting ceased, and she gained 2 lb. in weight.

Six months later she was re-admitted on account of a return of the vomiting. Bougies were passed down the osophagus on three oceasions, but no improvement was noticed. A fluid diet again gave the child relief from her symptoms.

Her third admission was a year later, again owing to a return of vomiting, and again she improved on a fluid diet. On her discharge, an X-ray screen examination showed no delay in the passage of an opaque meal through the osophagus, and she was able to take such solids as bread and butter, and mashed potatoes.

The child remained in good health for a year, and then developed tuberculous meningitis. At the post-mortem examination the diagnosis of tuberculous meningitis was confirmed. The mediastinal glands were caseous, but were not attached to, nor pressing upon, the resophagus. The oesophagus, both on its external and internal surfaces, appeared normal. No evidence could be found of constriction of the wall, nor of hypertrophy of the musculature, or ulceration of the mucosa. Microscopical examinations of the nesophagus, taken at various levels, showed nothing abnormal. The only other feature at the autopsy was the congenital absence of the left kidney and ureter.

The cause of the cesophageal obstruction in this case is difficult to determine with certainty. The likeliest explanation in our view is that the obstruction was due to a congenital narrowing of the oesophagus which, with the normal growth of the parts, gradually underwent a spontaneous cure. Our reasons for adopting this attitude are detailed at length in the discussion which follows on the first 10 cases as a group.

\section{Group 1: Clinical survey.}

Atiological factors.-Five of the ten preceding cases were prematurely born, one at 7 months, the other four during the 8th month. This number of premature babies forms a high proportion, but in view of the small total number of cases, one cannot draw any conclusion from this curious feature. With regard to the place in the family, four children were the outcome of first pregnancies, the remainder occupying various places in the family from the 2nd to the 5th.

There were eight boys affected to two girls, which gives a proportion almost identical with that found in such other congenital abnormalities of the alimentary tract as congenital stenosis of the pylorus, and idiopathic dilatation of the colon.

In one instance (Case 4) a paternal uncle had suffered from an exactly similar illness, which had undergone a spontaneous cure when he was 15 years old. In his case, no bougies had been passed.

The Wassermann reaction was performed in two cases, and was negative in both. Clinical evidence of syphilis could not be found in any of the cases. In only one instance (Case 10) was there evidence of tuberculosis, and, although the mediastinal glands in that child were caseous, they were not attached in any way to the osophagus. The infectious fevers were not more frequent than might be found in any small group of children, and in most cases they 
produced no effect upon the symptoms, except in Case 6 . In this boy, the vomiting ceased abruptly with the onset of paratyphoid fever, and did not recur until the temperature had fallen to normal.

Symptomatology.- The symptoms arose in all cases during the first year of life. In seven instances, the vomiting, which was the first and most severe symptom, actually dated from birth. Of the remaining cases, one commenced to vomit at 10 days old, another at 6 weeks, and the third at 11 months, when weaning on to solid food was attempted. In most of those children who vomited from birth, the vomiting was noticed to become worse when solid food was introduced into the diet. The fact that the romiting was in one case delayed until the child was weaned, and was aggravated at that time in others, is what would be expected if the ossophageal obstruction were of the nature of a congenital stricture, for such a condition would be liable to different degrees of severity in different cases. Presumably in those cases where the vomiting dated from birth, the narrowing was more pronounced than in those where this symptom was delayed until the attempt to give solid food was made.

The most prominent symptom was romiting, which was often described as effortless, and generally occurred during or immediately after a meal. The vomited material consisted of undigested food, mucus and saliva. In some instances the vomitus was copious, and obviously consisted of more than one meal. In one child (Case 1) the vomit was reported to have been occasionally bile-stained. In most cases, a feature of the vomiting was its periodic exacerbation into a severe bout lasting up to a week, during which both solid and fluid food were returned. During the interval between such bouts, which was usually about three weeks, vomiting occurred occasionally, particularly if solid food was given. The significance of these periods of increased vomiting is uncertain ; they may possibly mark an aggravation in the degree of the stricture by inflammatory swelling, with perhaps superadded spasm as the result of an attempt to force solid particles of food through the stricture. Certainly in some cases, attempts to pass esophageal bougies gave rise later on to an increase of the symptoms, probably as a result of injury to the stricture.

The effects of such persistent vomiting appeared in the stunting and poor nutrition which were evident in all the cases. The accompanying table shows the actual amount of under-development noted, and it will be seen that in several instances the weight was not more than half the normal for the age, while the height was also below the normal standard.

Constipation was a frequent symptom, which one would expect in view of the prolonged starvation. The constipation ran parallel with the vomiting.

$\mathrm{X}$-ray evidence.-X-ray examination in all these cases has demonstrated that the level of the obstruction in the oesophagus is well above the dome of the diaphragm, so that it seems clear that neither spasm of the diaphragm nor abnormalities of the cardiac sphincter can have any bearing upon the pathogenesis of the condition under discussion. In order to be certain that obstruction at the cardiac orifice would give an obviously different $\mathrm{X}$-ray picture, the nesophagus of a boy who died at the age of 4 years, was ligatured just at its entry into the stomach. The osophagus was then filled with a bismuth meal, 
and an X-ray picture of the cadaver was taken. The picture showed the bismuth shadow continuing well below the level of the diaphragm, the appearance being exactly similar to that seen in adult cases of " cardiospasm ' or "achalasia of the cardia.'

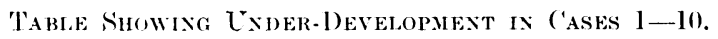

\begin{tabular}{|c|c|c|c|c|c|}
\hline \multirow[t]{2}{*}{ C'ase } & \multirow{2}{*}{$\begin{array}{l}\text { Age } \\
\text { in years }\end{array}$} & \multicolumn{2}{|c|}{ Height in inches } & \multicolumn{2}{|c|}{ Weight in pounds } \\
\hline & & Expected & Actual & Expected & Actual \\
\hline 1 & 3 & 35 & 27 & 33 & 15 \\
\hline 2 & 6.1 & 46 & 44 & 46 & 40 \\
\hline 3 & 3 & 35 & 34 & 33 & 17 \\
\hline 4 & 2 & - & - & 28 & 14 \\
\hline 5 & 11 & 56 & 53 & 70 & 55 \\
\hline 6 & $5 \frac{1}{2}$ & 42 & 38 & 43 & 35 \\
\hline 7 & $4 \frac{1}{2}$ & - & - & 39 & 22 \\
\hline 8 & 13 & 59 & 50 & 78 & $43 \frac{1}{2}$ \\
\hline 9 & (i & - & - & 46 & $33 \frac{1}{2}$ \\
\hline 10 & 4 & - & - & 37 & 24 \\
\hline
\end{tabular}

The site of obstruction in our cases appears to lie approximately half-way between the level of the bifurcation of the trachea and the cardia, at the level of the seventh thoracic vertebra.

One may sometimes be misled when examining these children under the $\mathrm{X}$-ray screen, because the obstruction, although great enough to prevent the passage of solid food, is not always sufficiently severe to interfere with the swallowing of fluids. This is particularly likely to be the case in children who do not vomit until towards the end of the first year, when solid food is being added to the diet. If such cases are screened while they are swallowing an opaque fluid, it may be seen to pass down the oesophagus without apparent hindrance. It is better to give the children an opaque solid to swallow, such as a bismuth biscuit, as by this means an oesophageal obstruction may be revealed when an opaque fluid has failed to do so.

Pathology.-Although the preceding ten cases form a clinical group with well-defined characteristics, it is difficult to place them on an uniform pathological basis. It may be that there is more than one morbid process concerned. The post-mortem evidence in the two cases which came to autopsy is at first sight conflicting, for while one (Case 1) showed a definite organic stricture, the other child (Case 10), who had experienced complete relief of symptoms for a year before death, showed no abnormality of the œsophagus. It is possible that if the opportunity had arisen of examining the osophagus of Case 10 while the œsophageal symptoms were present, some evidence of abnormality would have been found.

Acquired stenosis, such as follows the swallowing of caustics, can safely be excluded since in no case was there a history of the swallowing of any irritant. In addition the level of obstruction was not that usually found in cases of stricture due to caustics. 
Certain features gathered from our clinical survey seem to bear upon the pathogenesis of these cases. The onset of symptoms during the first year, often actually from birth, suggests that the osophageal obstruction was congenital, and this view is in no way invalidated by the fact that in two instances (Cases 2 and 5) the onset of vomiting was delayed until the end of the first year. In both these children the later history showed that the degree of the stricture was insufficient to hinder the passage of fluids, and therefore it was not until solid food was taken that symptoms appeared.

Case 10 may be taken as a typical example of the whole group. Here we have an uncomplicated case consistently treatcd by fluid diet only, which went on to complete cure, and in which death from incidental disease rendered an examination of the assophagus possible. The œesophagus was carefully examined, and sections at various levels were made. No evidence of stricture, hypertrophy or inflammation was found. The osophagus in fact was absolutely normal. It will be profitalle to discuss the pathogenesis of this group in the light of the evidence afforded by this case, and to illustrate the discussion by reference to the other cases where additional factors operated.

At least two possible explanations arise. These cases may be (1) examples of achalasia of the middle or lower end of the oesophagus ; or (2) the obstruction may be due to a congenital narrowing of the middle or the lower third of the œsophagus.

(1) Achalasia.-We can find no record in the literature of a case of achalasia occurring in the middle of the oesophagus, nor at the junction of the middle and lower thirds. Further, the normal condition of the osophagus in Case 10 was most unlike the descriptions of it in cases of achalasia of the cardia, in which there is always hypertrophy and usually dilatation of the muscular wall of the esophagus. To ascribe the cause of Case 10 to achalasia is to assume that cases of achalasia treated by fluid diet alone will undergo spontaneous cure, with the production of a normal oesophagus from one which was previously hypertrophied and dilated. Achalasia is, however, notoricus for its persistence when untreated by bougies. Bougie treatment of the cases under discussion tended to aggravate the trouble. Finally, as mentioned above, all these cases commenced vomiting from birth, or as soon as any attempt to give food more solid than milk was made. Achalasia in childhood is very uncommon, but as will be shown later, when it occurs it is a disease of later childhood rather than of infancy. These considerations render it unlikely that achalasia is the cause of the obstruction in the cases of this group.

(2) Congenital abnormality.-The osophagus has a double origin. The upper or para-tracheal part arises from the retro-pharyngeal segment of the foregut, while the lower or retro-tracheal part is developed from the pre-gastric segment of the foregut. Setting aside atresia and other fatal anomalies, congenital œsophageal obstruction at the level seen in our cases may arise in two ways. Either the junction of the two segments may be narrowed, or the lower segment in part or in whole may be narrowed, due to inadequate growth. We believe that under suitable conditions of treatment, spontaneous cure can 
oecur in a erertain time by the growth of the esophagus to its normal size and calibre. The length of time is uncertain, but in Case 10 cure occurred at the age of $3 \frac{1}{2}$ years. A study of the other cases shows that the length of time required for cure varies, and is probably adversely influenced by the forcible dilatation of the oesophagus. Such a conception accounts for the success that was obtained by treating these cases simply on a fluid diet. Had achalasia been the true explanation of these cases, bougie treatment should have given more gratifying results than were actually obtained.

The possibility of an element of spasm in several cases is suggested by the variability of the symptoms. There occurred in some of these children definite bouts of severe vomiting, with intervals of comparative freedom (Cases 1, 4, $5,7,9,10)$. These periodic exacerbations probably depended upon a recurring spasm superimposed upon a congenital narrowing of the esophagus. The spasm was possibly associated with injury or irritation of the osophagus at the site of the stenosis by unsuitable or stagnant food. In Case 6, the freedom from vomiting during paratyphoid fever may have been due to the presence of a spa;modic element in the case, which was abolished during the fever.

Examples of esophageal obstruction due to hysteria have been recorded, but the age of onset of symptoms in the ceses under consideration discounts such an explanation.

It is our opinion that the cases we have described should be regarded as examples of congenital narrowing or stenosis of the osophagus, with in some instances a secondary spasmodic element. Recovery is possibly brought about by the gradual growth of the parts, until eventually the obstruction is literally outgrown, a process which has its parallel in the gradual disappearance of the symptoms of congenital laryngeal stridor.

In 1920, Ashby described a group of 5 children with symptoms similar to those of our group. In one of his examples, a boy aged 4 years who had vomited from birth, post-mortem examination showed a fibrous stricture of the oesophagus one inch above the diaphragm. Only a narrow probe could be passed through the stricture. Ashby regarded these cases as primarily spasmodic, the inflammatory stricture being a later development.

Treatment.-Various lines of treatment, by operation, bougies, and diet, have been carried out on the cases we have described. An cpen operation was done in one case (Case 8), but was not successful. Ordinary œesophageal bougies were passed on three children : in two no improvement took place ; in the third improvement was only temporary. In addition, mercury-filled bougies were used on three cases, two of which improved, but sufficient time has not yet elapsed to say if this will be maintained : in the other child (Case 6) the use of the heavy bougie was followed by a definite contraction of the lumen of the stenosis, from which a long and arduous recovery was gradually made. Treatment by means of a prolonged fluid diet only was used consistently in four cases, three of which are cured, while the fourth was free of symptoms on discharge from hospital a few months ago. Cases 1 and 7 were at the time of admission to hospital in a very bad condition and died shortly afterwards, offering no opportunity for effective treatment. 
The most satisfactory results were obtained by giving a fluid diet over a long period, possibly for two or three years. Such treatment demands great patience, but is justified by results. Attempts to effect a speedier cure by more active measures, especially by bougie treatment, are not only unlikely to be successful, but may actually aggravate the condition, and make it worse.

Greig ${ }^{6}$ in 1921 drew attention to the clinical manifestations of congenital strictures of the oesophagus, and in urging their recognition as a clinical entity, he emphasized the value of treatment on dietetic lines alone, without the use of bougies. While our paper was in course of preparation, Beatty ${ }^{7}$ published 57 cases of congenital stenosis of the œsophagus. His paper includes a full bibliography. He describes two varieties of congenital stenosis of the cesophagus. The first consists of a local narrowing of the lumen of the esophagus without pathological changes in the wall, and on this latter point he distinguishes these cases from examples of acquired stenosis. The presence of pathological changes in the œesophagus at the level of the stenosis does not, however, entirely exclude the possibility that the narrowing was congenital, for as a result of trauma from the attempted passage of bougies, or from stagnation of food above the stricture, injury to the mucosa might occur and be followed by an inflammatory reaction. This would eventuate in fibrous constriction where formerly there was simply a congenital narrowing. With regard to treatment, Beatty is in agreement with Greig that a fluid diet offers the best chance of recovery.

The other variety of congenital obstruction, which has been well described by Guisez ${ }^{8}$, consists of a thin incomplete membrane which stretches across the csophagus. This type has been treated with success by the intentional rupture of the membrane by means of bougies or with the osophagoscope.

In any child in whom the presence of a congenital narrowing of the osophagus is suspected, it is essential to examine the patient by X-rays after he has swallowed an opaque, and preferably solid, meal. If by this means the diagnosis is confirmed, the next procedure should be a very careful œsophegoscopy to determine whether the stricture consists of an incomplete septum across the osophagus, or a simple narrowing of the lumen. In the latter case, persistent treatment by a fluid diet should be instituted, and the blind passage of bougies avoided.

Group II. (CASES 11 and 12.) ObStrction at I.Evel of Diaphragin.

A study of the cases of congenital stenosis tabulated by Beatty shows that the majority occurred in the lower half of the osophagus, some actually at the level of the diaphragm. A few were situated in the upper half. The two following cases have clinical resemblances to those we have already described, but the account of them has been delayed until now because the level of the obstruction was at a lower level in the osophagus.

Case 11. F. W., boy aged 5 years, was admitted to hospital in 1910 with the history that he had had recurrent attacks of vomiting since birth, and that these had been accompanied by constipation.

On admission the boy weighed only $16 \mathrm{lb}$. All attempts at oral feeding gave rise to vomiting, and so recourse was made to feeding by rectal enemata. The child rapidly weakened and died. At the post-mortem examination, the ossophagus was progressively dilated and the musclo 
hypertrophied down to the level of the diaphragm, where the lumen of the cesophagus was definitely narrowed, although the muscle at this point was not thicker than that of the osophagus above.

(ase 12. V. J., boy aged $3 \frac{1}{2}$ years, was admitted to hospital with the history that since birth (he was born prematurely at 8 months) he had had periodic bouts of vomiting, and had lived almost entirely on fluids.

On admission the child was thin, weighing $22 \mathrm{lb}$. There was extensive odema of the face, hands and feet, and the gums were ulcerated. His condition was at first regarded as due to nephritis, which the presence of blood in the urine seemed to confirm. Renal function tests proved to be normal, and the Wassermann reaction was negative. The boy's general condition gradually improved, but periodic vomiting continued, and he failed to gain weight. He was then suspected of suffering from oesophageal obstruction, and osophageal bougies were passed on several occasions. These met with no obstruction, but nevertheless gave temporary relief from the attacks of vomiting. X-ray examination showed that a bismuth meal passed quickly into the stomach.

The boy continued to vomit at intervals, and eventually developed a fatal broncho-pneumonia six months after his, admission.

At the post-mortem examination, the csophagus was dilated and the muscle hypertrophied. These changes commenced about an inch below the cricoid cartilage, and terminated at the diaphragm, where the oesophagus underwent a thick fibrous constriction.

\section{Discussion of Group II.}

It will be noticed that in both these children (Cases 11 and 12) the vomiting dated from birth and occurred in bouts, being in these respects similar to the previous cases. Also at both autopsies narrowing of the œsophagus was found. It is interesting to note that in the first case, in which bougies had not been passed, narrowing of the oesophagus without fibrosis was present, while in the second case, in which bougies were used, there was a fibrous stricture.

We regard these cases as examples of congenital stenosis of the csophagus at the level of the diaphragm.

\section{Cardiospasm.}

Although many of the preceding cases were originally regarded as examples of cardiospasm, reasons have been given for considering them to be due to congenital stenosis of the œsophagus. The question arises whether the neuromuscular disorders of the cardia, variously known as cardiospasm, phrenospasm, and achalasia of the cardia, which are found in adults, ever occur in infancy or childhood. Other conditions which are ascribed to neuro-muscular defects, such as Hirschsprüng's disease and idiopathic dilatation of the bladder, give rise to symptoms during infancy, so that by analogy a similar state of affairs at the lower end of the œsophagus might be expected to occur at that age. According to Hurst ${ }^{9}$, the symptoms of achalasia of the cardia may be met with at any age.

The following case, for which we are indebted to Dr. Paterson, under whose care the child was admitted to the Westminster Hospital, is a typical example of cardiospasm. The symptoms first appeared when the patient was 8 years old. 
l. R., boy aged $8 \frac{1}{2}$ years, was admitted to hospital with a history that for 4 months he had vomited after almost every meal. Both fluids and solids were returned. The appetite was good, but recently he had been losing weight. Previously his health had been good.

On admission, he weighed $43 \mathrm{lb}$. There were no abnormal physical signs. An $\mathrm{X}$-ray examination (Fig. 12) showed an appearance typical of cardiospasm. The osophagus can be seen dilated and filled with bismuth down to the level of the cardiac sphincter, well kelow the level of the dome of the diaphragm.

A No. 16 mercury-filled bougie was passed down the cesophagus, enterirg the stomach without difficulty. The bougie was then passed daily, and the boy made steady improvement, rapidly losing his symptoms and gaining $3 \mathrm{lb}$. in weight in the first month. He was taught to pass the bougie himself, and on discharge he was supplied with a bougie for use at home.

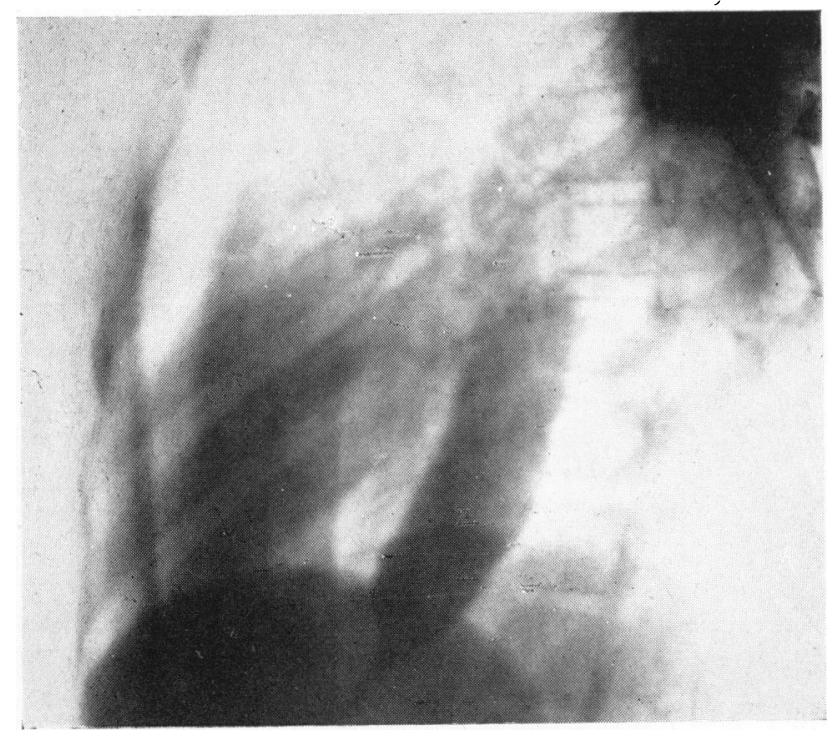

Fic. 12.

We have been able to discover very few such cases in the literature. In Rolleston's original case ${ }^{10}$, a boy who died of cardiospasm had had symptoms since 8 years of age. Sears ${ }^{11}$ described a boy in whom symptoms appeared at the age of 7 years. Messeloff, Shulman and Buckstein ${ }^{12}$ recorded a typical instance in a boy who had had symptoms since the age of 10 years. These authors collected eleven cases of 'cardiospasm' in children from the literature, but the descriptions of some of these are so incomplete that it seems uncertain whether they were really examples of cardiospasm. Thus, in the one case that came to post-mortem examination, there was found a fibrous stricture of the cesophagus 5 inches above the cardia. In six cases there was neither radiological nor post-mortem evidence to support the diagnosis. Spasm of the cardia was found in an X-ray examination of a boy aged 10 years, but the age of onset of the symptoms was not given. Of the remainder, an infant aged 10 months had had attacks of vomiting for 6 months; X-ray examination showed a spasm of the cardia, which lasted for 30 seconds before part of the opaque meal passed on into the stomach (Méry). In describing this case, the 
author considered that the cause of the spasm lay in excessive swallowing of air. Another child aged 3 years had had attacks of choking and vomiting after meals since birth; X-ray examination showed spasm at the cardia. The spasm was quickly relieved by giving atropine and benzyl benzoate (Bruce). In a third case, a boy aged 12 years had suffered from regurgitation of food from the oesophagus since 3 years old : X-ray examination showed obstruction at the cardia. The child was treated with Plummer's hydrostatic dilator (Seegar).

In the case of a boy aged 5 years reported by Castronovo ${ }^{13}$, vomiting of food from the osophagus had occurred since birth. The X-ray picture was exactly similar to those seen in adult cases of cardiospasm, and the author's title of 'Congenital Spasm of the Cardia' is a concise description of the case. A similar instance was described by J. A. M. Cameron ${ }^{14}$, of a boy who died when 6 years old. This child had suffercd from bouts of vomiting since the age of 6 months. At post-mortem examination, the osophageal wall was hypertrophied, the thickest portion being at the cardia; in this respect the case differs essentially from the cases which Hurst has described as achalasia of the cardia, in which the œesophageal wall is hypertrophied down to, but not including the cardiac sphincter. We have not been able to find conclusive evidence that achalasia of the cardia occurs in infancy, although it does rarely appear in the later years of childhood. Spasmodic contraction of the cardiac sphincter does occasionally occur in infants, as evidenced by the cases of Méry, Bruce, Castronovo, and Cameron.

\section{SIMMARY.}

Ten examples of congenital narrowing of the osophagus at the level of the seventh thoracic vertebra are reported, and the clinical picture of this condition is described. Treatment by persistent fluid diet is recommended, the passage of bougies being likely to do more harm than good. Two cases of congenital stenosis at the level of the diaphragm are also recorded. The question of the occurrence of spasm of the cardia and achalasia of the cardia in infancy and childhood is discussed.

We wish to express our thanks to the Medical St $\mathrm{fff}$ of the Hospital for Sick Children, Great Ormond Street, for their permission to make use of the hospital records.

\section{REFERENCES.}

1. Cautley, E., Brit. J. Child. Dis., Lond., 1917, XIV, 1.

2. Hutchison, R., Proc. Roy. Soc. Med., Lond., 1922, XVI (Child Sect.), 42.

3. Niller, R., Arch. Dis. Child., Lond., 1927, II, 189.

4. Paterson, 1). H., Brit. J. Child. Dis., Lond., 1921, XVIII, 27.

5. Ashby, H. T., Proc. Roy. Soc. Med., Lond., 1920, XIII (Child Sect.), 146.

6. Greig, D. M., Edinburgh Med. J., 1921, XXVIII, 11.

7. Beatty, C. ('., Brit. J. Child. Dis., Lond., 1928, XXV, 237.

s. (iuisez, J., Diagnostic et Traitement des Rétrécissements de l'ḱsophage et de la Trachée, Paris, 1923,46 .

9. Hurst, A. F., Quart. J. Med., Oxford, 1914, VIII, 300.

10. Rolleston, H. D., Trans. P'ath. Soc., Lond., 1896, XLVII, 37.

11. Sears, W. G., Brit. J. Child. Dis., lond., 1928, XXV, 48.

12. Messeloff, Shulman, \& Buckstein, Amer. J. Child. Dis., Chicago, 1928, XXXV. 426.

13. ('astronovo, E., La Pedriatria, Naples, 1925, XXXIII, 483.

14. ('ameron, J. A. M., Arch. Dis. Child., Lond., 1927, II, 358. 